Original Article

\title{
Tissue repair in post extraction sockets of Cavia cobaya induced by a combination of propolis and graft
}

\author{
Utari Kresnoadi $^{1 *}$, Roselini Halim ${ }^{2}$, Hananah Oktalidial Putri ${ }^{2}$, Mutiara Aryanita ${ }^{2}$, Imam Safari Azhar ${ }^{1}$ \\ ${ }^{1}$ Department of Prosthodontics, Faculty of Dental Medicine, Universitas Airlangga, Surabaya, Indonesia, 60132 \\ ${ }^{2}$ Undergradute student, Faculty of Dental Medicine, Universitas Airlangga, Surabaya, Indonesia, 60132
}

\begin{abstract}
Propolis, hive defensive substance that contains caffeic acid phenethyl ester, can affect the migration and proliferation of cells involved in the healing process. Combination of propolis extract with BBG are predicted to fasten the wound healing, especially its effect on angiogenesis, macrophages and collagen density. In this study, we aimed to analyze the effect of a propolis combination and BBG in proliferating new blood vesselsand macrophages, while also increasing the collagen density of the post-extracted tooth socket healing process in Cavia cobaya. 56 C. cobaya, whose left mandibular incisorshad been extracted, were subsequently divided into four groups on the basis of the substances used to fill their sockets, namely; control, BBG, propolis extract, and a combination of BBG, and propolis extract. The subjects sacrificed on either the third or seventh day. Histopathological samples were produced using HE and MT staining. The results were subjected tosome statistical analysis tests: one-way analysis of variance (ANOVA), Tukey's honestly significant difference (HSD), Kruskal Wallis, and Mann Whitney. Significant increases $(\mathrm{p}<0.05)$ were detected between the PEG and PEG+Propolis groups and also between the PEG and PEG+BBG+Propolis combination groups. However, an insignificant increase ( $>0.05$ ) was identified between the PEG and BBG groups. In conclusion, a combination of BBG and propolis can increase the number of new blood vessels and macrophages together with the degree of collagen density in the healing process of post-extraction tooth sockets of $C$. cobaya.
\end{abstract}

Keywords: blood vessels, collagen density, macrophage, propolis, tooth extraction

Received: 8 June 2020 Revised: 13 June 2020 Accepted: 20 June 2020

\section{Introduction}

Tooth extraction constitutes the process of removing a tooth from its socket located in the alveolar bone (Balaji, 2009). This results in traumatic injury to both the hard and soft tissue (Hupp et al., 2014), for example, separation of the periosteum from the bone and damage to the vascularity which induces an acute inflammatory response mediating the bone resorption necessary for initiation of the wound healing process (Jamjoom \& Cohen, 2015). Bone resorption can, in turn, induce changes in the morphology and dimensions of alveolar bone, thereby greatly influencing the success of dental treatment. Therefore, preservation of post-extracted tooth sockets is necessary to reduce excessive alveolar bone resorption by tissue engineering (Kresnoadi et al., 2018).

In addition, tissue wound healing requires high vascularity to satisfy the need for oxygen and address the nutritional factor. Lack of vascularization increases the risk of bacterial and fungal infections which complicate wound management.(Schiff, 2009) New blood vessels begin to appear when the chronic inflammatory phase commences on the third day and peaks around the seventh day (Honnegowda et al., 2015; Okonkwo \& Dipietro, 2017).

* Corresponding Author:

Utari Kresnoadi

Department of Prosthodontics, Faculty of Dental Medicine,

Universitas Airlangga, Jl. Mayjend Prof. Dr. Moestopo No. 47,

Surabaya, Indonesia, 60132

Phone: +62315030255 Fax: +62315020256

e-mail: utari-k@fkg.unair.ac.id
Bovine bone graft (BBG) constitutes an osteoconductive material employed as a scaffold. Ideally, BBG material should be progressively resorbed and replaced with vital bone (Larjava, 2012; Rombouts et al., 2016). The use of $\mathrm{BBG}$ in post-extraction ridge preservation is common practice. However, its stability is insufficient to produce the anticipated result. The combination of anti-inflammatory agent, propolis-BBG, plays a role as an osteoconductive material. Osteoconduction is the ability of the graft to bind with the new osteoblast cells and osteoprogenitor cells, therefore it can stabilize and support bone regeneration with osteoblast cell growth (Kresnoadi et al., 2017).

Many contemporary herbal and natural ingredients, including propolis, are employed in the field of medicine. Propolis contains, among other substances, flavonoids and Caffeic Acid Phenethyl Ester (CAPE) which are both anti-inflammatory and anti-oxidant in their effects. Puspasari et al. (2018) asserted that its content can affect the migration and proliferation of cells involved in the healingprocess. However, no scientific study has been undertaken into the use of a combination of propolis extract with BBG in socket wound healing, especially its effect on angiogenesis, macrophages and collagen density. Against a background of limited prior research, this study sought to investigate the amount of new blood vessels, macrophages and collagen density in the post-extracted tooth sockets of Cavia cobaya induced by a combination of propolis extract and BBG on the third and seventh days. 


\section{Method}

Ethical clearance for this research (No. 281/HRECC.FODM/V/2019) was issued by the Health Research Ethics Committee of the Faculty of Dental Medicine. The research constituted an experimental laboratory study using random samples with post testonly control group design. The samples analysed consisted ofactively mobile, healthy, male,3-3.5 month old, C. cobaya weighing 300-350 g which were divided into four groupseach containing seven members.

Identification of propolis extract was carried out at the Industrial Research and Consultation Center, Surabaya, Indonesia, using 4-6 week old Trigona sp. bee propolis obtained from an apiary in Lawang, East Java. The results showed propolis extract to consist of $1.28 \%$ flavonoid, $2.56 \%$ caffeic acid, $1.05 \%$ apigenin, $0.82 \%$ saponin, $1.03 \%$ quercetin, and $1.15 \%$ terpenoids.

After the subjects had been anesthetized with $0.2 \mathrm{cc}$ ketamine (Pfizer), their left lower incisors were extracted and the resulting sockets treated in a manner according to the group of which they were members. For example, 25 $\mathrm{g}$ of polyethylene glycol (PEG) was administered to the members of control groups, while those of BBG groups received a combination of $0.5 \mathrm{~g}$ of $\mathrm{BBG}$ and $24.5 \mathrm{~g}$ of PEG. There were four main groups, namely control (PEG only), BBG, propolis, and propolis + BBG group. In propolis groups, $0.5 \mathrm{~g}$ of propolis extract and $24.5 \mathrm{~g}$ of PEG were received by their members, with those of propolis+BBG groups were administered with $0.5 \mathrm{~g}$ of propolis extract, $0.5 \mathrm{~g}$ of $\mathrm{BBG}$, and $24 \mathrm{~g}$ of PEG. Following this process, the tooth sockets of subjects were sewn up with Polyamida monofilament DS 12 3/8 c, 12 mm, 6/10 meth, 0.7 sterile (Braun Aesculap) sewing thread according to standard surgical protocol in Dr. Soetomo General Hospital. Those groups were sacrificed, and their mandibular bone extracted on the third and the seventh day.

Production of histopathological $C$. cobaya socket samples was completed at the Dr. Soetomo Anatomical Pathology Laboratory, Surabaya using HematoxylinEosin (HE) stain to observe blood vessels and macrophages (Kresnoadi et al., 2018), while Masson Trichrome (MT) stain was employed to enable observation of collagen density (Rachmanita et al., 2019). The samples were subsequently examined by means of a light microscope (Shimadzu ${ }^{\circledR}$, Japan) at 400x magnificationin order to establish the number of new blood vessels and macrophages present in the socket. A histopathological scoring parameter of 0-4 (0 representing 'Not found' and 4'Very tight') was employed to assess the density of the collagen. The details of scoring parameter was: $0=$ if there was not found any collagen fibers density in the wound area, $1=$ if there was low collagen fiber density in the wound area $(25 \%), 2=$ if there was medium collagen fiber density in the wound area $(50 \%), 3=$ if there was tight collagen fiber density in the wound area $(75 \%)$, and $4=$ if there was very tight collagen fiber density in the wound area $(100 \%)$. The resulting data was tested statistically by means of a Kolmogorov-Smirnov Test, a Levene's Test, a one-way ANOVA test, Kruskal-wallis test, Mann-Whitney test, and a Tukey HSD using IBM Statistical Product and Service Solutions (SPSS) version 20.

\section{Results}

The results relating to the amount and standard deviation of new blood vessels in the tooth sockets of all groups examined on the third and seventh days are contained in Figure 1, while the histopathological sample of new blood vessels in the tooth socket examined on the third and seventh days can be seen in Figures 2 and 3.

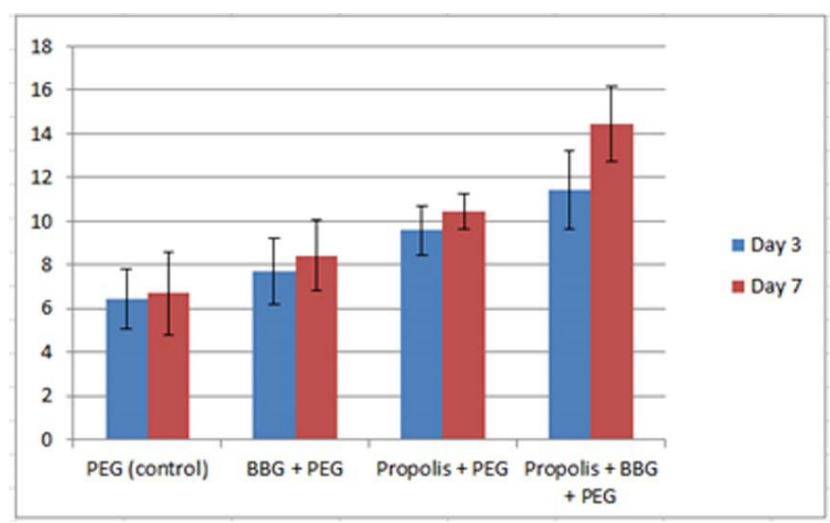

Figure 1. The amount and standard deviation of new blood vessels in the tooth socket examined on the third and seventh days.

Based on the analysisof the Kolmogorov-Smirnov and Levene's test results, the sample was found to be normally distributed and homogeneous. One-way ANOVA and Tukey HSD analysis results showed that in the groups examined on the third day, there were significant differences between control group, propolis group $(\mathrm{p}=0.003)$, and propolis $+\mathrm{BBG}$ group $(\mathrm{p}=0.000)$; as well asbetween $\mathrm{BBG}$ group and propolis $+\mathrm{BBG}$ group $(p=0.000)$. On the other hand, there were no significant differences between control group and BBG group $(p=0.384)$, BBG group and propolis group $(p=0.115)$, or propolis group and propolis $+B B G$ group $(p=0.115)$.

In the groups examined on the seventh day, one-way ANOVA and Tukey HSD analysis results indicated significant differences between control group, BBG group and propolis group compared to propolis $+\mathrm{BBG}$ group $(\mathrm{p}=0.000)$; or control group compared to propolis group $(\mathrm{p}=0.001)$. On the other hand, no significant differences existed between control group compared to BBG group 4 $(p=0.197)$; or $B B G$ group compared to propolis group $(\mathrm{p}=0.105)$. 

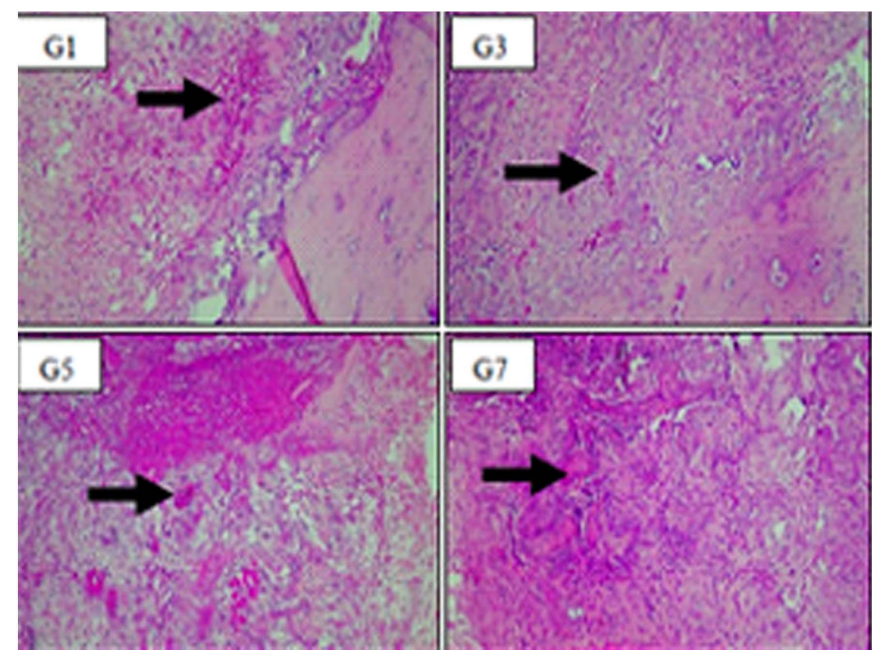

Figure 2. The histopathological sample picture with HE staining of new blood vessels in the tooth sockets of each group examined on the third day. The arrow indicates the blood vessel lumen

The results of the amount and standard deviation of macrophages in the tooth socket of all groups examined on the third and seventh days can be seen in Figure 4. The histopathological sample of macrophages in the tooth socket examined on the third and seventh days can be seen in Figures 5 and 6.

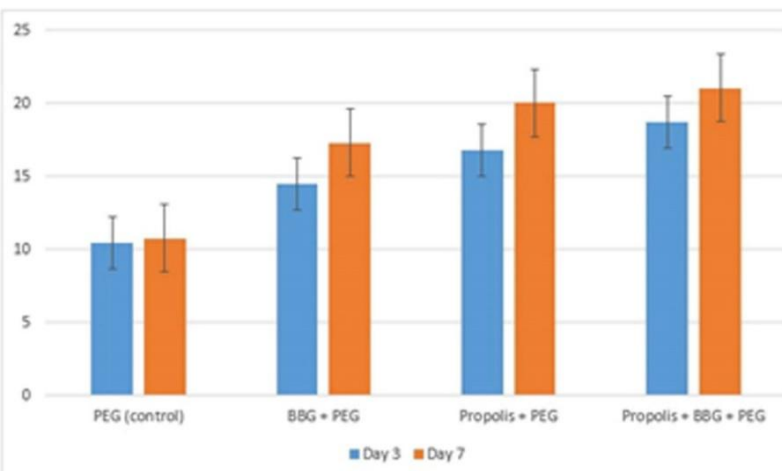

Figure 4 The amount and standard deviation of macrophages in the tooth socket examined on the third and seventh days.

Statistical analysis of the One-way ANOVA and Tukey HSD tests showed that on day 3 the difference in the number of bone graft-induced macrophages between the control group and the treatment group had a significance of $\mathrm{p}=0.073$ (Table 1$)$.

Table 1. The $\mathrm{p}$ value of each groups on day 3

\begin{tabular}{lllll}
\hline & Control & Propolis & BBG & BBG+Propolis \\
\hline Control & & $0.002^{*}$ & 0.073 & $0.000^{*}$ \\
Propolis & & & 0.448 & 0.63 \\
BBG & & & & 0.055 \\
BBG+Propolis & & & & \\
\hline
\end{tabular}

The difference between the control group and the treatment group that had been induced with propolis had a significance of $p=0.002$. The difference between the control and treatment groups induced by BBG+propolis had a significance of $\mathrm{p}=0.000$, while the significance of

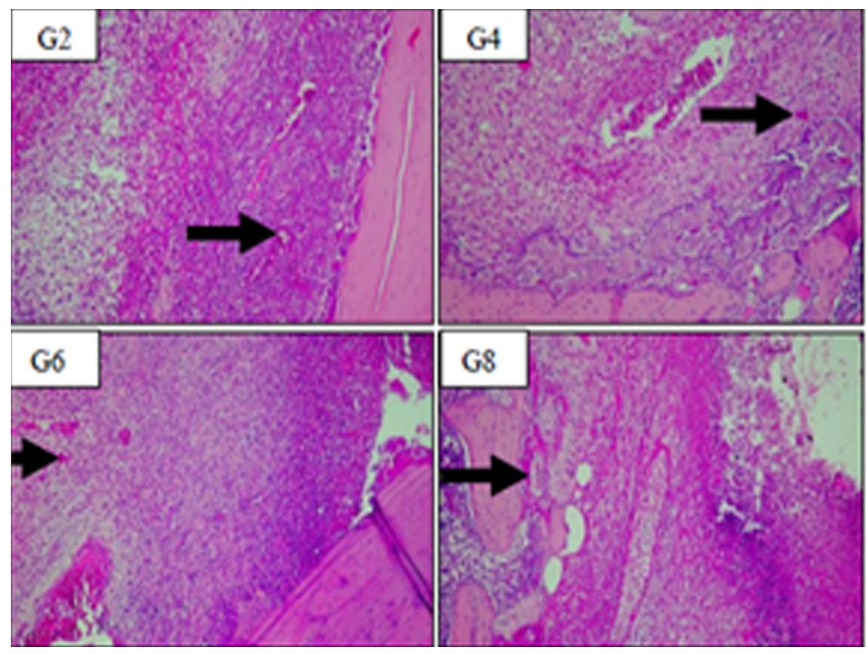

Figure 3. The histopathological sample picture with HE staining of new blood vessels in the tooth socket of each group examined on the seventh day. The arrow indicates the blood vessel lumen.

the difference between the treatment group induced by bone graft and the treatment group induced by propolis

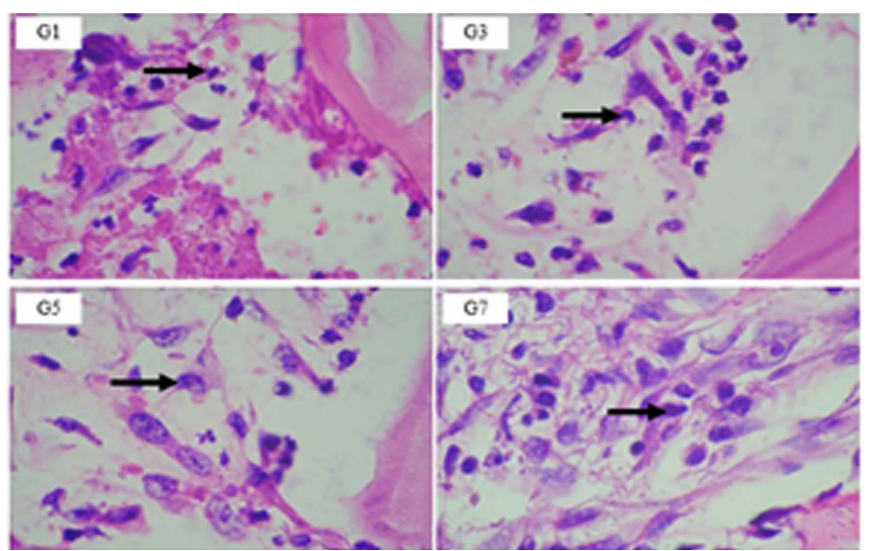

Figure 5 The histopathological sample picture with HE staining of macrophages in the tooth socket of each group examined on the third

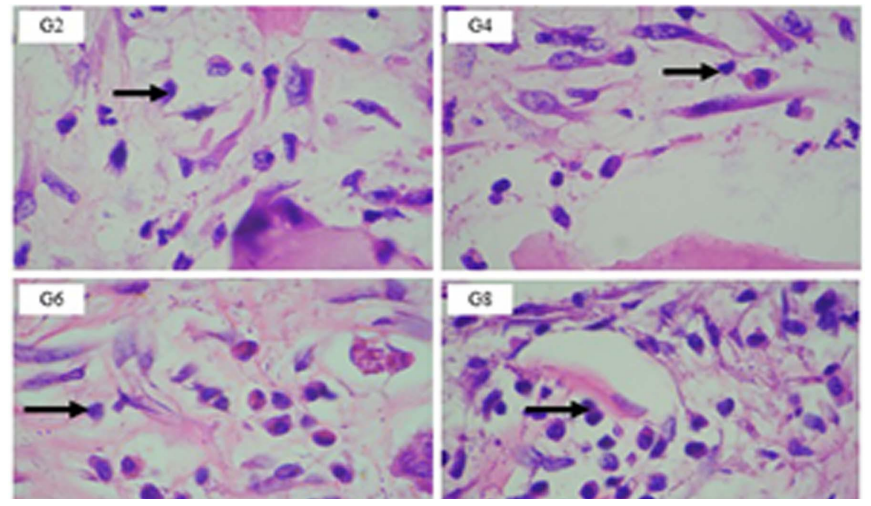

Figure 6 The histopathological sample picture with HE staining of macrophages in the tooth socket of each group examined on the seventh

The significance of the difference between the treatment group induced by bone graft and the treatment group induced by $\mathrm{BBG}+$ propolis amounted to $\mathrm{p}=0.055$, 
while that between the treatment group induced by propolis and the treatment group induced by $\mathrm{BBG}+$ propolis was $\mathrm{p}=0.630$. On day 7 , the difference in the amount of macrophages between the control group and the treatment group induced by bone graft had a significance $\mathrm{p}=0.001$, while the difference between the control group with the treatment group induced by propolis had a significance of $\mathrm{p}=0.000$ (Table 2).

Table 2. The $\mathrm{p}$ value of each groups on day 7

\begin{tabular}{lllll}
\hline & Control & Propolis & BBG & BBG+Propolis \\
\hline Control & & $0.000^{*}$ & $0.001^{*}$ & $0.000^{*}$ \\
Propolis & & & 0.228 & 0.889 \\
BBG & & & 0.058 \\
BBG+Propolis & & & & \\
\hline
\end{tabular}

The difference between the control group and the treatment group induced by $\mathrm{BBG}+$ propolis had a significance $\mathrm{p}=0.000$, whereas that between the treatment group induced by bone graft and the treatment group induced by propolis had a significance of $p=0.228$. The difference between the treatment group induced by bone graft and the treatment group induced by $\mathrm{BBG}+$ propolis had a significance of $\mathrm{p}=0.058$, while that between the treatment group induced by propolis and the treatment group induced by $\mathrm{BBG}+$ propolis had a significance of $\mathrm{p}=0.889$.

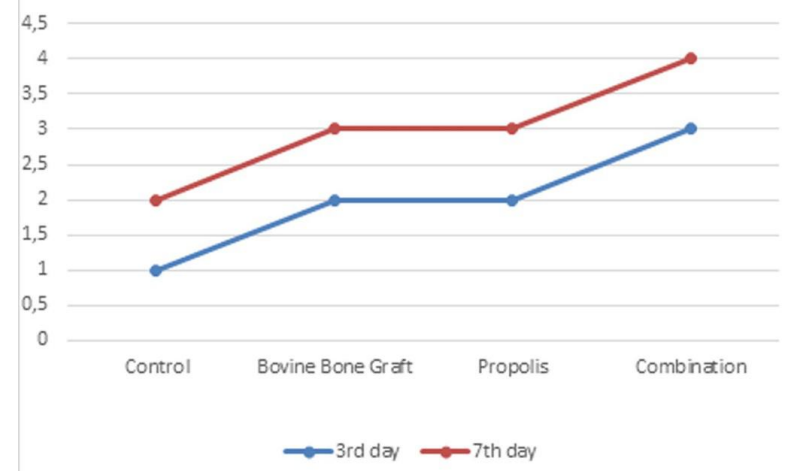

Figure 7. Graph of Collagen Density Median Scoring

The results of median scoring of collagen density in Figure 7, and the intepretation of the collagen density scoring parameter by histopathological sample of collagen in the tooth socket examined on the third and seventh days in Figure 8.
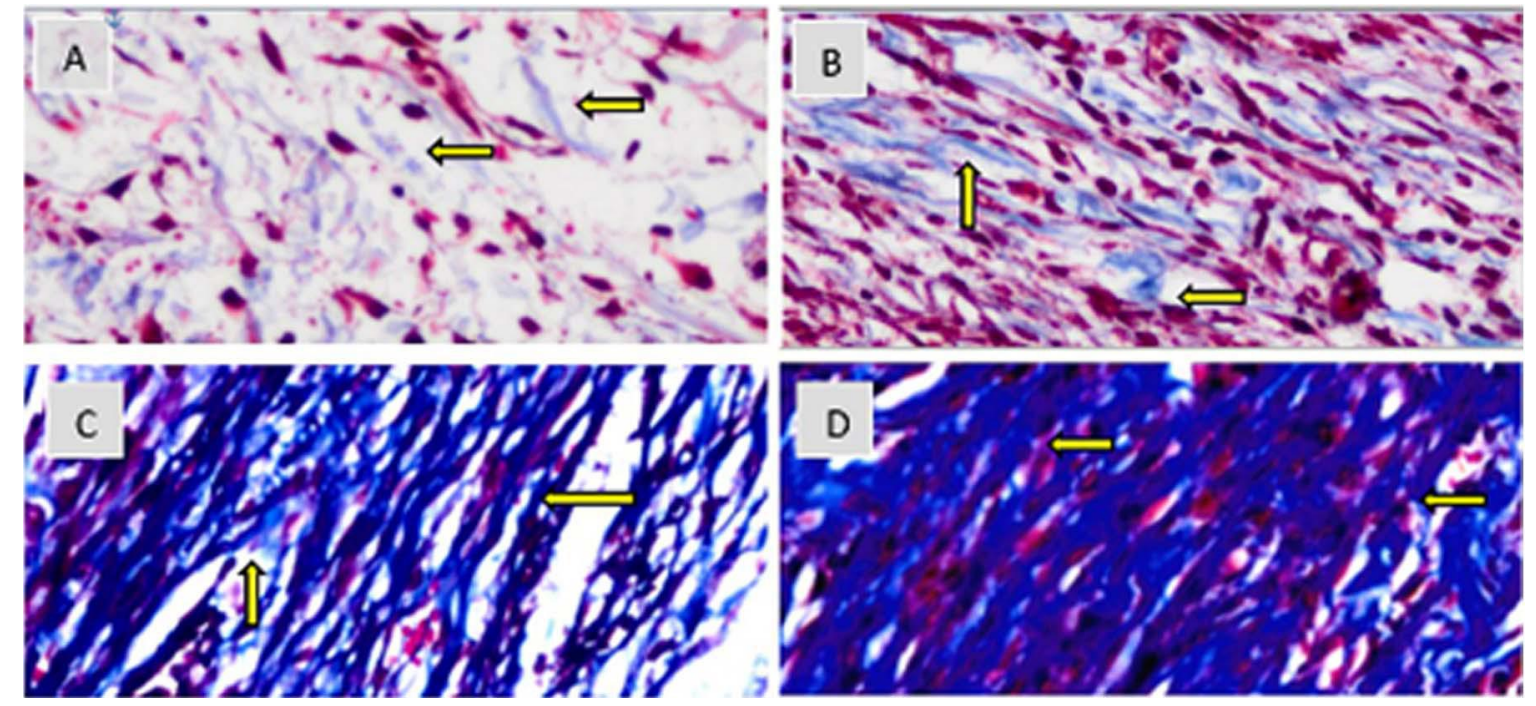

Figure 8. Interpretation of collagen density. Collagen fibers appear as blue and red veins. (A) Scoring 1 at 400x magnification (B) Scoring 2 at 400x magnification (C) Scoring 3 at 400x magnification (D) Scoring 4 at 400x magnification.

\section{Discussion}

The post-extraction wound healing process encompasses several phases, namely; hemostasis, inflammation, proliferation, and remodelling (Schiff, 2009). The inflammatory process will trigger bone resorption by osteoclasts resulting in a decrease in the size of the alveolar ridge. On the other hand, alveolar ridge height is important for the retention and stabilization that constitute prerequisites to successful dental treatment. Therefore, tissue engineering for socket preservation is essential (Kresnoadi et al., 2018), while vascularization also constitutes an important factor in wound healing (Schiff, 2009).

The activated cells that play the primary role in the inflammatory process are neutrophils whose function is to clean microorganisms and cellular debris in the injured area. However, their production of substances such as proteases and Reactive Oxygen Species (ROS) can also induce excessive inflammation. During the initial phase of the wound, in addition to neutrophils, type 1 macrophages are triggered which, in turn, activate the nuclear factor kappa-B (NfKB) pathway, thereby 
inducing the release of proinflammatory mediators such as Tumor Necrosis Factor- $\alpha$ (TNF- $\alpha$ ), Interleukin-1 (IL-1), and Interleukin-6 (IL-6) (Quader, Islam, Saifullah, Majumder, \& Hannan, 2013). On cessation of neutrophilactivity, they will be phagocyted by macrophages which subsequently differentiate into type 2 macrophages (reparative macrophages) and secrete growth factors such as PDGF and TGF- $\beta$ which initiate the migration and proliferation of fibroblasts. At the same time, macrophages and fibroblasts secrete pro-angiogenic factors, such as VEGF and FGF, which then increase the formation of new blood vessels (Dohle et al., 2014).

This investigation involved the use of propolis with an active substance content of $2 \%$, a decision based on previous preliminary research whose findings indicated that this concentration produced the most effective postextraction wound healing results in $C$. cobaya. These research subjects were selected due to their widespread availability, docility, ease of handling, and common wound healing process with humans. The exclusive selection of males was intended to avoid the possibility of hormonal changes within the bodies of the C. cobaya which might, in turn, influence the healing process (Fox et al., 2015). Moreover, BBG constitutes a xenograft type transplant derived from cows which possesses a high osteoconductive capacity (Larjava, 2012).

The results indicated that the number of new blood vessels in group 3 (BBG + PEG) day 3 was higher yet demonstrated no significant difference with that of group 1 (PEG) $(\mathrm{p}>0.05)$. The same situation prevailed between group $4(\mathrm{BBG}+\mathrm{PEG})$ day 7 and group $2(\mathrm{PEG})(\mathrm{p}>0.05)$ day 7. BBG is said to possess the ability to increase VEGF (Saghiri et al., 2016) which plays a role in increasing angiogenesis. However, angiogenesis is not only influenced by VEGF but, rather,by many contributory factors, both stimulators and inhibitors. The angiogenesis stimulators include aFGF (FGF-1), bFGF (FGF-2), TGF- $\alpha$, TGF- $\beta$, PGE2, TNF- $\alpha$, VEGF, and EGF,while angiogenesis inhibitors include thrombospondin-1, tissue inhibitors of matrix metalloproteinases, interferon alpha / beta / gamma, angiostatin, and endostatin (Honnegowda et al., 2015). Therefore, securing insignificant results is possibly due to other factors that influence the angiogenesis process in addition to VEGF.

In group 5 (Propolis + PEG), a proliferation of blood vessels occurred and a significant difference compared to group 1 (PEG) on the third day after extraction $(\mathrm{p}<0.05)$ existed. The increase in their number was also evident and this produced a significant difference $(p<0.05)$ in group 6 (Propolis + PEG) day 7 compared to group 2 (PEG) day 7.

The results produced support the theory that propolis has numerous properties including anti-inflammatory and anti-oxidant. The flavonoids contained in propolis are anti-inflammatory since theyinhibit COX-2, thereby decreasing proinflammatory cytokines through the Nf-KB pathway (Rajoo et al., 2018). Caffeic Acid Phenethyl Ester (CAPE) is an anti-oxidant present in propolis which specifically inhibits the activation of Nf-KB by preventing interactions between $\mathrm{Nf}-\mathrm{KB}$ protein and DNA,resulting in ROS production being prevented.
Furthermore, CAPE is also reported to be capable of inhibiting the production of ROS derived from neutrophils (Akyol et al., 2015). According to Rajoo et al. (2014), CAPE can also bind to free radicals which have the effect of further reducing pro-inflammatory cytokines (Rajoo et al., 2014). In addition, the anti-inflammatory properties of CAPE are reputed to significantly reduce pro-inflammatory factors induced by NF-kB such as TNF- $\alpha$, IFN- $\gamma$, IL-2, IL-6, iNOS, and IL-8 (Armutcu et al., 2015). Therefore, there is an acceleration of the inflammatory process, followed by differentiation of macrophages into a reparative form that releases growth factors such as FGF, VEGF, and TGF- $\beta$ supportive of the process of angiogenesis (Dohle et al., 2014).

In this research, the group which was treated with a combination of propolis extract, BBG, and PEG performed better results than the other treatment groups (PEG, BBG + PEG, propolis + PEG) both on the third and seventh days $(p<0.05)$. This possibly occurs because the combination of propolis and BBG extract can engender osteoconductive properties and scaffold from BBG that support the healing process, in addition to the antiinflammatory and anti-oxidant properties of propolis which promote the process of angiogenesis. Moreover, the number of blood vessels on the seventh day exceeded that of the third day. This is in line with the statements made by Okonkwo and Dipietro (2017) that the process of angiogenesis reaches its peak on the seventh day.

Tooth extraction is a procedure frequently performed in the field of dentistry which is followed by the wound healing process. Initially, following the occurrence of an injury, platelets will accumulate in the area to form clots and produce cytokines and certain GF such as PDGF and TGF- $\beta$ will induce neutrophils. Macrophages perform their function as phagocytes for three days after the occurrence of lesions and will continue to do so as a means of promoting the formation of granulated tissue and the process of angiogenesis with the support of fibroblasts, keratinocytes, and endothelial cells until the seventh day. Furthermore, the formation of connective tissue and the process of angiogenesis will be followed by a phase of bone remodeling when osteoclasts die through a process of apoptosis and osteoblasts promote the formation of new cells (Ahsania, 2019; Cohen \& CohenLévy, 2014; Wang et al., 2017).

This research was conducted on the third day during which the macrophages entered the lesion area to phagocytosis (Cohen \& Cohen-Lévy, 2014) and on the seventh day when the macrophages supported the proliferation phase of the wound healing process by producing several interleukins and growth factors (Wang et al., 2017). In this study, propolis extract was used because it produces an immunostimulatory effect that can increase the number of macrophages which it is anticipated will accelerate the wound healing process due to tooth extraction (Herawati et al., 2017). This study also involved the use of BBG which it is expected will support bone formation.

In this study, the results of a combination of observation and statistical analysis indicated an increase in the number of macrophages in each group on both the third and seventh days. This is consistent with Ahsania's 
research (2019) that the presence of materials containing flavonoids can increase the amount of macrophages.

Analysis of the data on day 3 confirmed that the group induced with propolis and those induced with BBG and propolis presented significant differences compared to the control group. This is due to the fact that propolis can increase TLR-2 expression within which TLR activates macrophages with the result that when TLR expression increases the amount of macrophages also rises (Herawati et al., 2015). Moreover, propolis can improve the function of macrophage phagocytes and also enhance the release of interferon-gamma (IFN- $\gamma$ ), interleukin-6 (IL-6), and interleukin-1 $\beta$ (IL-1 $\beta$ ) (Hariri, 2019).

Analysis of the data on day 7 showed that the BBGinduced group, the propolis-induced group, and the BBG and propolis-induced group demonstrated significant differences compared to the control group. The BBGinduced group showed an increase in the amount of macrophages with a significant difference compared to the control group. This was because on the seventh day, during the proliferation phase of the wound healing process, granulated tissue formation and angiogenesis were supported by macrophages during the production of GF and IL, culminating in the remodeling phase (Cohen \& Cohen-Lévy, 2014).

The results of this study prove that induction of a combination of propolis extract and BBG can increase the number of macrophages in tooth extraction sockets. In a study conducted by Perkasa (2016) analyzing the effect of propolis on the number of osteoclast cells, propolis, as an antioxidant, was shown to increase bone remodeling by accelerating the differentiation of osteoblast cells, thereby minimizing bone resorption. Study by Kresnoadi et al. (2020) also stated that combination of propolis extract and bovine bone graft was shown to increase the expressions of HSP70 and osteocalcin, accelerating the differentiation of osteoblast cells. In addition, it was proved that propolis can also accelerate the wound healing process. Similarly, the article by Pascoal et al. (2014) regarding the role of propolis in infected wounds explained that propolis can accelerate the wound healing process by stimulating the proliferation of keratinocytes.

During the post-extraction wound healing process, a complex and dynamic process occurs during which the missing cellular structure and tissue layers are replaced. The process of wound healing is divided into four phases, namely; hemostatic, inflammatory, proliferative, and remodeling (Mercandetti, 2019). During the proliferative phase, fibroblasts synthesize collagen which plays an important role in the wound healing process by reshaping the extracellular matrix that reattaches damaged tissue (Hochstein \& Batia, 2014). Significant synthesis of collagen by fibroblasts occurred on day 3 and reached a peak on day 7 (Velnar et al., 2009). Alveolar ridge bone resorption is a biological phenomenon occurring after tooth extraction which, while non-preventable, can be minimized by the application of socket preservation regenerative material (Allegrini et al., 2008; Jamjoom \& Cohen, 2015).

In this study, the results indicated a significant increase in collagen density between the control group and the group to which BBG had been administered on both the third day $(\mathrm{p}=0.024)$ and seventh day $(\mathrm{p}=0.037)$. This finding was in accordance with those of Lucaciu et al. (2019) that bovine bone mineral can be seen to be osteoconductive since it affects bone regeneration by stimulating osteoblast attachment, osteoblast proliferation and greater mineralization of osteoblasts. During the process of bone formation by osteoblasts, histogenesis produces bone matrix proteins such as collagen fibers (Rutkovskiy et al., 2016).

The results indicated a significant increase in collagen density between the control group and the group to which propolis had been administered on both the third day $(p=0.000)$ and the seventh day $(p=0.023)$. Propolis is one potential material capable of accelerating wound healing. The indirect effect of propolis on fibroblasts occurs through the mediation of macrophages which produce IL1, FGF, and TNF. FGF can induce fibroblast proliferation, whereas one function of IL-1 is to mediate tissue remodeling and repair. Both IL-1 and TNF can trigger the proliferation of fibroblasts since they are chemotactic with regard to fibroblasts and further stimulate the synthesis of collagen (Asdar, 2016; Rutkovskiy et al., 2016).

The highest collagen density was achieved through the combined use of bovine bone graft and propolis. This combination significantly increased collagen density when compared to the control group on both the third day $(p=0.001)$ and the seventh day $(p=0.007)$. This finding is in accordance with the initial hypothesis, that the combined application of propolis and bovine bone graft can increase the density of collagen more effectively than their separate use.

This research is restricted to the histopathological examination of the quantity of blood vessels and macrophages, together with the density of collagen as a healing factor in post-extraction tooth socket wounds. Further studies should be undertaken incorporating immunohistological examination in order to develop an in-depth knowledge of the effect of a combination of propolis extract and BBG on the socket healing process.

From the analysis and discussion above, it can be concluded that the combination of propolis extract and BBG can increase the amount of new blood vessels, macrophages, and collagen density in the post-extraction socketsof C. cobaya.

\section{Acknowledgment}

The authors declare there is no conflict of interest.

\section{References}

Ahsania, F. (2019). Efek Ekstrak Biji Mahoni (Swietenia mahagoni) Terhadap Jumlah Sel Makrofag Pada Proses Penyembuhan Luka Pasca Pencabutan Gigi Tikus Wistar (Rattus norvegicus). Thesis. Universitas Airlangga.

Akyol, S., Akbas, A., Butun, I., Toktas, M., Ozyurt, H., Sahin, S., \& Akyol, O. (2015). Caffeic acid phenethyl ester as a remedial agent for reproductive functions and oxidative stress-based pathologies of gonads. Journal of Intercultural Ethnopharmacology, 4(2), 187.

Allegrini, S., Koening, B., Allegrini, M., Yoshimoto, M., Gedrange, T., Fanghaenel, J., \& Lipski, M. (2008). Alveolar ridge sockets preservation with bone grafting - Review. Annales Academiae 
Medicae Stetinensis, 54, 70-81.

Armutcu, F., Akyol, S., Ustunsoy, S., \& Turan, F. F. (2015). Therapeutic potential of caffeic acid phenethyl ester and its anti-inflammatory and immunomodulatory effects (Review). Experimental and Therapeutic Medicine, 9, 1582-1588.

Asdar. (2016). Pengaruh Propolis Terhadap Kolagenisasi Pada Proses Penyembuhan Luka Subkutan Punggung Mencit yang Diinduksi Bakteri Actinobacillus Actinomycefemcomitans. Fakultas Kedokteran Gigi Universitas Hasanuddin, 1-15.

Balaji, S. (2009). Textbook of oral and maxillofacial surgery. JP Medical Ltd.

Cohen, N., \& Cohen-Lévy, J. (2014). Healing processes following tooth extraction in orthodontic cases. J Dentofacial Anom Orthod, 17 304. doi:10.1051/odfen/2014006

Dohle, E., Bischoff, I., Böse, T., Marsano, A., Banfi, A., Unger, R. E., .. Gutenberg-university, J. (2014). Macrophage-mediated angiogenic activation of outgrowth endothelial cells in co-culture with primary osteoblasts. European Cells and Materials, 27, $149-165$.

Fox, J., Whary, L. A., Mark, G. O., Pritchett-Corning, K., \& Whary, M. (2015). Laboratory animal medicine (3rd ed.). London: Elsevier.

Hariri, M. Al. (2019). Immune's - boosting agent : Immunomodulation potentials of propolis. Journal of Family and Community Medicine, 26(1), 57-60. doi:10.4103/jfcm.JFCM

Herawati, I., Husin, U. A., \& Sudigdoadi, S. (2015). Pengaruh Ekstrak Etanol Propolis Terhadap Aktivitas dan Kapasitas Fagositosis pada Kultur Makrofag yang Diinfeksi Enteropathogenic Escherichia coli ( EPEC ). Majalah Kedokteran Bandung, 47(2), 102-108.

Hochstein, A., \& Batia, A. (2014). Collagen: Its role in wound healing. Wound Manage, 4(1), 104-109.

Honnegowda, T. M., Kumar, P., Govindarama, E., Udupa, P., Kumar, S. Kumar, U., \& Rao, P. (2015). Role of angiogenesis and angiogenic factors in acute and chronic wound healing. doi: $10.4103 / 2347-9264.165438$

Hupp, R. J., Ellis, E., \& Tucker, M. R. (2014). Contemporary oral and maxillofacial surgery. British dental journal, 215(2), 99-99.

Jamjoom, A., \& Cohen, R. (2015). Grafts for Ridge Preservation. Journal of Functional Biomaterials, 6(3), 833-848.

Kresnoadi, U., Ariani, M. D., Djulaeha, E., \& Hendrijantini, N. (2017) The potential of mangosteen (Garcinia mangostana) peel extract, combined with demineralized freeze-dried bovine bone xenograft, to reduce ridge resorption and alveolar bone regeneration in preserving the tooth extraction socket. Journal of Indian Prosthodontic Society2, 17(3), 282-288.

Kresnoadi, U., Raharjo, T., \& Rostiny, R. (2018). Effects of mangosteen peel extract combined with demineralized freeze - dried bovine bone xenograft on osteocalcin , collagen 1 , and osteoblast as alveolar bone regeneration in socket preservation. The Journal of the Indian Prosthodontic Society, 18(2), 118-121.

Kresnoadi, U., Rahayu, R. P., Ariani, M. D., \& Soesanto, S. (2020). The Potential of Natural Propolis Extract Combined with Bovine Bone Graft in Increasing Heat Shock Protein 70 and Osteocalcin on Socket Preservation. European Journal of Dentistry, 14(01), 031-037. doi:10.1055/s-0040-1701921

Larjava, H. (2012). Oral wound healing: cell biology and clinical management. John Wiley \& Sons.

Lucaciu, O., Apostu, D., Mester, A., Campian, R., Gheban, D., \& Miron, R. (2019). Atelo-Collagen Type I Bovine Bone Substitute and Membrane in Guided Bone Regeneration: a series of clinical cases and histopathological assessments. Histology and Histopathology, 1061-1071. doi:10.14670/HH-18-108

Mercandetti, M. (2019). Wound Healing and Repair. Retrieved June 15 , 2020, from https://emedicine.medscape.com/article/1298129overview

Okonkwo, U. A., \& Dipietro, L. A. (2017). Diabetes and wound angiogenesis. International Journal of Molecular Sciences, 18(7), $1-15$.

Oryan, A., Alemzadeh, E., \& Moshiri, A. (2017). Potential role of propolis in wound healing: Biological properties and therapeutic activities. Biomedicine and Pharmacotherapy, 98(2018), 469483. doi:10.1016/j.biopha.2017.12.069

Pascoal, A., Feás, X., Dias, T., Dias, L. G., \& Estevinho, L. M. (2014) The Role of Honey and Propolis in the Treatment of Infected Wounds. Microbiology for Surgical Infections: Diagnosis, Prognosis and Treatment, 221-234. doi:10.1016/B978-0-12 411629-0.00013-1

Perkasa, M. I. A. (2016). Aplikasi Gel Ekstrak Propolis pada Soket Pasca Eekstraksi Gigi Cavia cobaya Terhadap Jumlah Sel Osteoklas. (Doctoral dissertation, Universitas Airlangga).

Puspasari, A., Harijanti, K., Soebadi, B., Hendarti, H. T., Radithia, D., \& Ernawati, D. S. (2018). Effects of topical application of propolis extract on fibroblast growth factor-2 and fibroblast expression in the traumatic ulcers of diabetic Rattus norvegicus. Journal of oral and maxillofacial pathology, 22, 54-58.

Quader, S. H., Islam, S. U., Saifullah, A., Majumder, M. F. U., \& Hannan, J. (2013). In-vivo Studies of the Anti-inflammatory Effects of Spirulina platensis. Journal of Pharmacognosy and Phytochemistry, 2(4), 70-80.

Rachmanita, R. T., Primarizky, H., F, F., Setiawan, B., Agustono, B., \& L., S. A. (2019). Effectivity Of Bitter Leaf Extract (Vernonia Amygdalina) Topically On Collagen Density On Incision Wound Healing In Rats (Rattus Norvegicus). Jurnal Medic Veteriner., 2 $36-41$.

Rajoo, M., Parolia, A., Pau, A., \& Amalraj, F. D. (2014). The Role of Propolis in Inflammation and Orofacial Pain: A Review. Annual Research \& Review in Biology, 4(4), 651-664.

Rombouts, C., Jeanneau, C., Camilleri, J., Laurent, P., \& About, I. (2016) Characterization and angiogenic potential of xenogeneic bone grafting materials: Role of periodontal ligament cells. Dental Materials Journal, 35(6), 900-907.

Rutkovskiy, A., Stensløkken, K.-O., \& Vaage, I. (2016). Osteoblast Differentiation at a Glance. Medical Science Monitor Basic Research, 22, 95-106. doi:10.12659/MSMBR.901142

Saghiri, M., Asatourian, A., Garcia-godoy, F., \& Sheibani, N. (2016). The role of angiogenesis in implant dentistry part II : The effect of bone-grafting and barrier membrane materials on angiogenesis. Med Oral Patol Oral Cir Bucal, 21(4), 526-537.

Schiff, B. A. (2009). Wound Healing. In Complications in Head and Neck Surgery (2nd ed., pp. 40-42). Philadelphia: Elsevier Inc.

Velnar, T., Bailey, T., \& Smrkolj, V. (2009). The Wound Healing Process: An Overview of the Cellular and Molecular Mechanisms. The Journal of International Medical Research, 37, 1528-1542. doi:10.1177/147323000903700531

Wang, P. H., Huang, B. S., Horng, H. C., Yeh, C. C., \& Chen, Y. J. (2017). Wound healing. Journal of the Chinese Medical Association, 81(2), 94-101. doi:10.1016/j.jcma.2017.11.002

Yahfoufi, N., Alsadi, N., Jambi, M., \& Matar, C. (2018). The Immunomodulatory and Anti-Inflammatory Role. Nutrients, 10(1618), 3 